\title{
UNA SOCIEDAD TRADICIONAL PARA JÓVENES MODERNAS. JUVENTUD RURAL Y ASOCIACIONISMO FEMENINO EN LA ESPAÑA DEMOCRÁTICA
}

\section{A TRADITIONAL SOCIETY TO UP-TO-DAY YOUNG. RURAL YOUTH AND FEMALE ASSOCIATIONISM IN DEMOCRATIC SPAIN}

Teresa María Ortega-López

Universidad de Granada (España)

ORCID: 0000-0002-4486-9715

Recibido el 7-9-2016 y aceptado el 15-12-2016

Resumen: A pesar de los avances jurídicos conseguidos tras la instauración de la democracia en España, la discriminación por razones de género, la falta de oportunidades para la formación, el desempleo o la dificultad para conciliar la vida familiar y laboral continuaron afectando al colectivo de las mujeres trabajadoras. Los mencionados agravios se vieron intensificados en el medio rural. Con la llegada de la democracia, los modelos de relación tradicional que habían prevalecido en la sociedad rural, en los que el papel de la mujer había sido secundario y pasivo, se vieron crecientemente enfrentados a un mundo marcado por pautas de modernidad urbana, dando paso, a partir de los años setenta, al afloramiento de un escenario potencialmente conflictivo. Fue entonces cuando las mujeres, especialmente las más jóvenes, emergieron haciendo gala de un protagonismo que históricamente se les había negado.

Palabras clave: Género, España rural, mujeres rurales, jóvenes rurales, asociacionismo, movimientos de mujeres.

Abstract: Despite the legal developments achieved after the establishment of the Spanish Democracy, the gender-based discrimination, the lack of opportunities for training, the unemployment or the difficulty to reconcile work and family life, continued to affect the collective of women workers in a negative way. The above-mentioned grievances were intensified in the rural areas. Af- 
ter the arrival of democracy, the models of traditional relationship that had prevailed in the rural society, in which the role of the woman was secondary and passive, were increasingly faced with a world marked by patterns of urban modernity, giving way, from the seventies onwards, to the outcrop of a potentially contentious situation. It was then when the rural women, especially the youngest, emerged dressed in a leading role that historically had been denied.

Key words: Gender, Rural Spain, rural women, rural youth, associationism, women's movements. 


\section{Introducción}

Occidente se caracteriza por ser una cultura hegemónicamente urbana que niega a su «otro» interno, los habitantes del campo. Haciendo un recorrido por algunas epistemologías, denominadas poscoloniales, que buscan crear un pensamiento dirigido a cuestionar los límites del proyecto de la modernidad, nos proponemos ver qué aspectos de estas teorías pueden dar luz a nuestro tema de investigación: las mujeres campesinas en la España democrática. Creemos que la contribución de los feminismos poscoloniales, son iluminadores para analizar las protestas de las campesinas de la España de fines de los setenta y primera mitad de los años ochenta del siglo pasado, y la llamativa invisibilidad que todavía hoy borra las acciones de estas mujeres, privándolas o dificultando su acceso a determinados derechos fundamentales. Al resaltar los aspectos borrados de la historia y del presente, estas teorías pueden darnos algunas pistas para pensar desde la práctica de sujetos y voces silenciadas por los saberes y sujetos hegemónicos.

Atendiendo a esto, nuestro trabajo se enmarca en una investigación iniciada hace algunos años que se propone estudiar las acciones llevadas a cabo por las mujeres habitantes del mundo rural de este país (siendo conscientes de la enorme complejidad y diversidad a la que aluden los conceptos de «mujer rural» y «mujer campesina») para conquistar derechos democráticos. Más específicamente, buscamos ver cómo aparecen (in)visibilizados para las mujeres, tras la instauración de la democracia, derechos tan elementales como el referido al acceso a la cotitularidad de la propiedad y demás recursos productivos, la salud, la educación, o la representación en el ámbito público e instancias políticas/sindicales que permiten la toma de decisiones para la organización, entre otras cosas, de la actividad económica en la que trabajan. Para ello, partimos del supuesto teórico que desarrollan algunas investigaciones que se han ocupado del empoderamiento de estas mujeres en América Latina, sumado al aporte del Grupo de Subalternistas de la India al analizar la llamada cuestión campesina ${ }^{1}$, de que la falta de estos derechos por parte de las mujeres es un elemento que las coloca en una posición de subordinación con respecto a los hombres. En esta negación de derechos a las mujeres se pone en juego, tal y como se ha advertido también por las investigaciones etnológicas y los análisis antropológicos, así como por las aportacio-

\footnotetext{
1 Véase Agarwal, 1998, pp. 530-581; Deere y León, 2000.
} 
nes derivadas de la ingeniería agronómica, la sociología rural y la geografía regional ${ }^{2}$, no sólo una subordinación económica sino toda una serie de condicionantes sociales, culturales, jurídicos, que hacen que la mujer ocupe una posición de subalternidad. La hipótesis que manejamos, siguiendo algunas de esas investigaciones, es que desde los ochenta, aunque fueron adoptadas en nuestro país significativas políticas en distintas esferas, en la práctica, la discriminación en el mundo campesino y rural se mantuvo, especialmente porque las mujeres no fueron consideradas ni actoras económicas, ni productoras de conocimientos, ni sujetos sociopolíticos integrales.

En este contexto de silenciamiento constante, consideramos que la apuesta de ruptura epistemológica y metodológica que proponen las corrientes poscoloniales/decoloniales es fundamental ${ }^{3}$. El esfuerzo de deconstrucción del paradigma moderno-eurocéntrico de conocimiento, que busca restituir a los grupos subalternos su memoria, obliterada por las narrativas imperiales y nacionalistas, y su condición de sujetos de sus propias historias puede hacer grandes aportes para despejar los interrogantes que todavía hoy continúan subsumiendo a las mujeres campesinas en tanto actores sociales con capacidad de agencia ${ }^{4}$. Del mismo modo, y esto es algo que también queremos dejar expuesto en el presente trabajo, la concepción de subalternidad como posición de (algunas) mujeres ha generado conceptual y políticamente la posibilidad de visibilizar lo invisibilizado por el discurso feminista occidental, que ha sido mostrar la diversidad de situaciones y experiencias que viven las mujeres, sus múltiples opresiones y las posibilidades (o no) que tienen de desplegar capacidades «agenciales» frente a contextos estructuralmente hostiles ${ }^{5}$.

2 Entre las primeras pueden consultarse Méndez, 1988, Aguilar Criado et al., 2001, y Pablo Cervera, Pérez Segovia y Vargas Llovera, 1995, pp. 85-93. Y entre las segundas: García Ramón, Salamaña y Cruz, 1994; García, 1977, y Zapatero Molinero y Jiménez Mejías, 1980.

${ }^{3}$ En esta dirección, los estudios feministas poscoloniales y los estudios decoloniales coinciden en proponernos otra ideología construida ahora desde las periferias, los bordes, los restos, las fronteras; desde quienes por colonizados/as, abyectos/as, bárbaros/as, incultos/as e irracionales, nunca «salieron en la foto». Expresión de Eduardo Galeano tomada por el periódico El País (2008) y reproducida en el artículo de Medina Martín, 2013, pp. 53-79.

${ }^{4}$ Guha, 2002; Mohanty, 2008, pp. 112-161.

${ }^{5}$ La construcción del «género» como categoría analítica ha servido al campo de las ciencias sociales para desvelar relaciones de subordinación de las mujeres en relación con el sujeto varón, no obstante, una revisión más rigurosa y a profundidad del uso de esta 
Para ilustrar nuestros argumentos utilizaremos la prensa y algunos de los informes, estudios y manifiestos, así como varias de las propuestas, enmiendas, comunicaciones, ponencias, reclamaciones y denuncias efectuadas, en los años setenta y ochenta, por mujeres pertenecientes a distintas organizaciones sindicales y asociaciones femeninas rurales de carácter profesional y radicadas en numerosas regiones y comunidades de la geografía española ${ }^{6}$. Creemos que el análisis de esa documentación inédita nos permitirá ofrecer una visión general y común, a pesar de la clara diferenciación de intereses existente entre mujeres pertenecientes a organizaciones jornaleras con respecto a aquellas que formaban parte de organizaciones de pequeños propietarios (Unió de Pagesos, UAGAs).

\section{Una aproximación al escenario de la juventud rural femenina a comienzos de la democracia.}

En los años iniciales de la década de los ochenta del siglo Xx, emergió en el medio rural español un asociacionismo protagonizado por mujeres, en su mayoría jóvenes, llamado a denunciar la vigencia de unas diferencias de género y una cultura androcéntrica que poco o nada hacía pensar que en 1977 se había implantado un régimen plenamente democrático en el país. A pesar de los avances conseguidos y las diferentes estructuras creadas en lo referente a la evolución de las mujeres, pasados los años, no era perceptible una igualdad real, situación ésta que se hacía más evidente en las zonas rurales donde los roles tradicionales de las mujeres estaban más arraigados. De hecho, para el caso de las jóvenes del medio rural la acentuación de las desigualdades y la exclusión se hacían más evidentes, esto es, la total falta de oportunidades de participación y de retribución por su trabajo, el desconocimiento de su aporte económico al hogar y a la sociedad, y sus escasas perspectivas de crecimiento autónomo. Ante tal si-

categoría y del encuentro con otros feminismos/feminismos poscoloniales, ha permitido identificar la existencia de una colonialidad del género que se expresa en la proliferación de trabajos en torno a las realidades de las mujeres blancas-occidentales, negando/desontologizando a las «otras mujeres», negras, indígenas, empobrecidas, musulmanas, con prácticas sexuales disidentes, migrantes, campesinas, et. Medina Martín, 2013, pp. 53-79.

${ }^{6}$ La documentación procede del «Fondo Documental de la Secretaría Confederal de la Mujer de CC.OO, depositada en la Fundación 1. ${ }^{\circ}$ de Mayo. Archivo del Trabajo de Comisiones Obreras (F1M). 
tuación, muchas optaban por migrar o, sin más, dirigieron sus esfuerzos a lidiar diariamente por el sostenimiento de sus familias y, por ende, por la sostenibilidad social de las áreas rurales.

$Y$ es que en los años siguientes al restablecimiento de la democracia en España, el modelo patriarcal seguía encontrando en el espacio rural un escenario fructífero para su desarrollo. Mientras en el medio urbano (y a pesar de las rémoras todavía perceptibles) algunos de los componentes de aquel modelo se habían ido eliminando, o cuando menos, «suavizando», en el rural se hacía muy difícil su arrumbamiento ${ }^{7}$. La promulgación de la actual constitución española, el 6 de diciembre de 1978, supuso la afirmación legal de la igualdad entre las mujeres y los hombres, y la no discriminación por razones de raza, sexo o religión, y su reconocimiento como principios inspiradores del ordenamiento jurídico de nuestro país ${ }^{8}$. Sin embargo, a pesar de la denominada «igualdad legal», un hecho materializado en diferentes normativas, las situaciones discriminatorias seguían existiendo y se manifestaban de muy diversas formas. La práctica evidenciaba que, para que las mujeres accedieran a la igualdad de oportunidades, no era suficiente con los cambios de leyes. Era preciso cambiar las actitudes y comportamientos, las formas de vida y las estructuras sociales que se mostraban como una barrera para el pleno desarrollo de las mujeres como personas con derecho a participar activamente en la cultura, el trabajo y la política.

El alcance de aquellas medidas de carácter jurídico y político no llegó con firmeza a las áreas rurales y las mujeres de los pueblos siguieron padeciendo desde entonces discriminaciones por su sexo ${ }^{9}$. La democracia no desterró allí el «reinado» doméstico. Incluso se puede decir que se perpetuó, favorecido por las características estructurales del medio rural, aquella arraigada consideración de que las mujeres debían centrarse en todo lo

7 Sampedro, 1996a.

${ }^{8}$ El artículo 14 de la Constitución Española establece que la población española es igual ante la ley, «sin que pueda prevalecer discriminación alguna por razón de nacimiento, raza, sexo, religión, opinión o cualquier otra condición o circunstancia personal o social». Por su parte, el artículo 9.2 señala que es a los poderes públicos a quienes corresponde «promover las condiciones para que la libertad y la igualdad [de las personas] y de los grupos en que se integra sean reales y efectivas; remover los obstáculos que impidan o dificulten su plenitud y facilitar la participación [de toda la ciudadanía] en la vida política, económica, cultural y social».

9 Ministerio de Medio Ambiente y Medio Rural y Marino, 2011, <http://www.mapa. es/es/desarrollo/desarrollo.htm>. 
que conllevaba el trabajo «reproductivo» quedando limitada de esta manera la participación pública y social de las mismas. Tal y como señala el propio Ministerio de Agricultura, «pese a que la inmensa mayoría de las mujeres agricultoras comparten las tareas agrícolas de las explotaciones familiares con sus parejas, estas actividades son vistas como una extensión de sus tareas domésticas y de cuidados» ${ }^{10}$.

Consolidada, pues, la democracia fueron muchas las desigualdades en las que siguieron viviendo estas mujeres de las zonas rurales, y muchas las razones que las llevaron a reclamar abiertamente la igualdad real y efectiva entre hombres y mujeres.

A través de las organizaciones sindicales y de las asociaciones específicamente femeninas, las más jóvenes visibilizaron las situaciones de opresión o discriminación de las que eran objeto, y la necesidad y el deseo de actuar en torno a la sustancial alteración de una realidad con la que lograr la afirmación de la diversidad de sus necesidades e intereses. En el seno de las diferentes organizaciones, y ayudadas por el nuevo contexto político y sociocultural que se abrió tras la consecución de la democracia, aquellas mujeres encontraron un marco adecuado para la elaboración de una interpretación de la realidad circundante, y de su particularizado presente, de una manera crítica, concibiéndola como un agregado experiencial de naturaleza esencialmente problemática y contradictoria que debía ser resuelta en una dirección de afirmación e imposición de los intereses del colectivo que se autoidentificaba con su específica defensa. El asociacionismo rural femenino se convirtió así, como se ha afirmado en alguna ocasión, en un «puente para la igualdad», en un instrumento eficaz que permitió a estas mujeres salir de los espacios y de los roles tradicionalmente asignados a su condición femenina y les ayudó a garantizar su participación en el espacio rural y en sus procesos de cambio.

Nuestra atención a las reivindicaciones y denuncias efectuadas por estas mujeres desde aquellas plataformas creadas a tal efecto nos permitirá al mismo tiempo poner énfasis en otras cuestiones que consideramos de gran importancia y sobre las que estimamos se deben profundizar en investigaciones futuras. En primer lugar, la «visibilidad» alcanzada por estas mujeres por sus acciones de protesta, ponen en cuestión el carácter supuestamente complaciente y transigente de las mujeres rurales y agrarias

${ }^{10}$ Ministerio de Agricultura, Alimentación y Medio Ambiente, 2016, <http://www.magrama.gob.es/es/desarrollorural/temas/igualdad_genero_y_des_sostenible/titularidad_compartida/>. 
al derribar imágenes arquetípicas difundidas por la literatura histórica y por el propio pensamiento feminista de la época ${ }^{11}$. La migración de muchas jóvenes, y el consiguiente proceso de masculinización y de envejecimiento de los pueblos ${ }^{12}$, puso en evidencia lo poco atractivas que resultaban para ellas lo que se había mostrado como las idílicas instituciones familiares y comunitarias, y el carácter androcéntrico y patriarcal presente en este medio. Detrás de esta decisión de abandonar el campo había algo más que necesidades puramente económicas o el deseo de encontrar nuevas oportunidades laborales y sociales. Las jóvenes que emigraron a la ciudad lo hicieron también por otras razones no tan materiales. Muy probablemente muchas se marcharon por su malestar, latente y/o manifiesto, con la invisibilidad y la subordinación que les consignaba una organización social patriarcal que perpetuaba las diferencias entre hombres y mujeres y, sobre todo, su papel subsidiario. Tal organización conformaba para las mujeres rurales una situación de aislamiento social, de inexistencia de un horizonte personal individual y de subordinación económica, y de dependencia familiar. Esto era así porque su trabajo fuera del hogar no se veía como un signo de promoción y de independencia personal, sólo se consideraba una «ayuda» y jamás se valoraba como equivalente al realizado por los hombres aunque fuera igual de duro. Sus labores se estimaban sólo como un «complemento» a las actividades que hacía el padre o, en su caso, el marido. Desde esta perspectiva, y tal y como rezaba en el imaginario individual y colectivo de las comunidades rurales, las mujeres campesinas sólo obtenían reconocimiento social y posibilidad de autoestima realizando las labores propias de la esfera reproductiva, es decir, adoptando el rol que se les atribuía como madres y esposas sumisas y abnegadas, como sufridoras de todos los males familiares y sociales. Así, las

11 Teresa López, presidenta de FADEMUR, la Federación de Asociaciones de Mujeres Rurales, nos advierte que se debe puntualizar, a la hora de definir a la mujer rural, un primer síntoma del desconocimiento y el escaso reconocimiento social que padecen: «Durante años se ha establecido un estereotipo de mujer sumisa, con poca iniciativa, que no corresponde a la realidad del mundo rural. Cuando nos preguntan cuál es el perfil de la mujer rural insistimos en que somos 7 millones de mujeres las que vivimos y trabajamos en el medio rural, entre las que hay de todo: mujeres más o menos formadas, más o menos resignadas, absolutamente emprendedoras o sin iniciativa, mayores, jóvenes... No corresponden a un arquetipo, se definen entre toda la diversidad que puede darse entre 7 millones de mujeres», <http://www.escapadarural.com/blog/propietarios/la-mujeren-el-mundo-rural/>.

12 Camarero, 2002, pp. 63-78. 
mujeres no desarrollaban una individualidad personal y podían ser consideradas como seres intercambiables, reemplazables o sustituibles por otra mujer (tía, abuela, madre, hermana, vecina) en su función de criar hijos, cuidar de la casa y trabajar - como ayuda - en el campo ${ }^{13}$.

Su emigración y sus denuncias nos desvelan, en segundo lugar, a unas mujeres «modernas» en una sociedad que aún cambiante seguía siendo tradicional en lo que respecta al sexo femenino ${ }^{14}$. Unas mujeres provistas de todo lo «nuevo» que acompañaron los movimientos sociales y políticos de los años sesenta y setenta, que apostaban por el ocio, la lectura, la moda, un nuevo estilo de vida y de vivir que las aproximaban a las jóvenes de las ciudades. Como dicen González y Gómez Benito, a mitad de los ochenta era perceptible que la situación de la juventud rural española estaba evolucionando a la par que la sociedad en su conjunto, registrando en ella los profundos cambios que estaba experimentado la sociedad española. No sólo cambió de forma extraordinaria su composición social interna y sus rasgos culturales, indican esos mismos autores, sino los perfiles de sus contraste con la población urbana. Las fronteras de lo rural y lo urbano se fueron difuminando en el seno de una sociedad cada vez más integrada y más móvil, al tiempo que desaparecían los límites ecológicos y, sobre todo, socioculturales de dicha distinción rural/urbana ${ }^{15}$.

De lo anterior conviene subrayar dos consideraciones más. La limitación que estas jóvenes del mundo rural, partícipes de los valores postmodernos y conscientes del nuevo escenario político, encontraron en la plena consecución de la igualdad de oportunidades, constituye una magnífica herramienta para rastrear el asentamiento y la consolidación de la democracia en el espacio local/municipal ${ }^{16}$. Y por otro lado, permite ampliar la percepción que hasta ahora se tenía de los movimientos de emancipación de las mujeres. Estos movimientos se han considerado hasta la

${ }^{13}$ Esta realidad que ha marcado nuestra historia, e incluso nuestro presente más inmediato, proviene de la ponencia realizada por Arnáiz, 1999, p. 65.

14 Sobre el peso de los valores tradicionales en las sociedades rurales y sus consecuencias sobre las mujeres puede consultarse: Díaz Méndez, 2005, pp. 63-84; Sampedro, 2009, pp. 179-193.

15 González y Gómez Benito, 2002, p. 85.

${ }^{16}$ Esta investigación conecta con la que están llevando a cabo varios profesores de la Universidad Pablo de Olavide de Sevilla y de la Universidad de Jaén. Véase al respecto los siguientes artículos: Herrera et al., 2012, pp. 73-96; Herrera, 2012, pp. 117-138, y del mismo autor, 2011, pp. 161-179. También: Herrera and Markoff, 2011, pp. 455-474. 
fecha como exclusivamente urbanos. Sin embargo, y a tenor de sus acciones, también es posible encontrar en el espacio rural respuestas explícitas de las mujeres para acabar con la fuente de su subordinación: el «orden patriarcal» expresado a través de la construcción social y un sistema específico de poder que justificaba la diferenciación entre hombres y mujeres ${ }^{17}$. De ahí que podamos considerar a las jóvenes del medio rural, como bien se ha advertido ya por algunos estudios ${ }^{18}$, más que reproductoras de un orden dado, deconstructoras y reconstructoras desde sus experiencias de nuevos modelos.

\section{Una sociedad rural y un sector agrícola en transformación y en clave de género}

En los años sesenta y setenta del siglo xx, España experimentó importantes cambios socioeconómicos. En lo que respecta al campo, en aquellas décadas se «liquidó» definitivamente la sociedad campesina tradicional que pasó a convertirse en una moderna sociedad agraria. También se disolvió la familia campesina que trasmutó en explotación familiar agraria capitalista. La agricultura tradicional dejó paso a una agricultura mecanizada, modernizada y dirigida al mercado internacional. Con la nueva agricultura intensiva se configuró un modelo de producción próximo a los modernos modelos industriales y empresariales.

Esta transformación e industrialización del sector primario propició el aumento de la producción pero redujo el empleo de mano de obra. En este contexto de desarrollo las mujeres fueron las primeras expulsadas del proceso de producción agraria. Muchas se marcharon a las ciudades ${ }^{19}$, y las que permanecieron en el medio rural fueron «confinadas» al espacio material y simbólico de lo doméstico. Aunque siguieron trabajando en el campo, lo hicieron como mano de obra «invisible». Como ha sido puesto de manifiesto en varias investigaciones, su trabajo ha estado ausente durante mucho tiempo de las mediciones estadísticas laborales ${ }^{20}, \mathrm{y}$ los medios de comunicación tampoco se han hecho eco de las funciones

17 En este sentido nos remitimos a los trabajos realizados por Ortega López, 2013, pp. 181-209; 2012, pp. 51-69, y 2015, pp. 61-74.

18 Santiso Sanz, 2002, p. 188.

19 Camarero, 1993.

20 Vicente-Mazariegos et al., 1991. 
que ellas asumen en la explotación agraria ${ }^{21}$. Las labores agropecuarias que han venido desempeñando no han tenido consideración de «trabajo productivo» a efectos de reconocimiento social y económico, sino de extensión de las tareas domésticas que les correspondía a las mujeres por su condición de género. Tal circunstancia se explica por otro fenómeno que en aquellos años aconteció en el medio rural español y de prácticamente todas las economías capitalistas occidentales.

El contacto con los mercados de producción y de consumo capitalista transformó las relaciones de producción. Como advirtió Rosario Sampedro, la modernización de la agricultura convirtió un espacio de producción familiar integral en un espacio de producción empresarial capitalista $^{22}$. Se produjo entonces una estricta división sexual del trabajo y se profundizó en la asignación de cometidos sociales diferenciados entre hombres y mujeres. La «crisis de la agricultura tradicional» ahondó la disociación entre «el espacio de lo productivo (conectado con el mercado, y por tanto fuente de poder, prestigio, autonomía, de extensión social en fin) y el espacio reproductivo (espacio del trabajo no mercantil, gratuito, inmensurable al no ser intercambiado, sin existencia social)» ${ }^{23}$. Y otorgó a cada miembro de la familia un diferente estatus económico y social según la función desempeñada en uno u otro ámbito.

Con la capitalización de la agricultura se produjo una apropiación masculina de la producción agraria. Las mujeres, por el contrario, vieron cómo su papel activo en las labores productivas desempeñadas antaño en los sistemas tradicionales de producción agraria ${ }^{24}$ quedó reducido, simplificado y minusvalorado. Ellas fueron desplazadas de la primera línea de un sector que cada vez contaba con una mayor revalorización, mayores cotas de poder y reconocimiento social y económico. Los hombres asumieron el protagonismo como trabajadores y empresarios agrarios, mientras las mujeres ocuparon una posición social subsidiaria, como «mujeres»o «hijas» del agricultor ${ }^{25}$. Así lo manifestaba una mujer integrante de la Federación de Uniones de Agricultores de la Región de Murcia (FUARM):

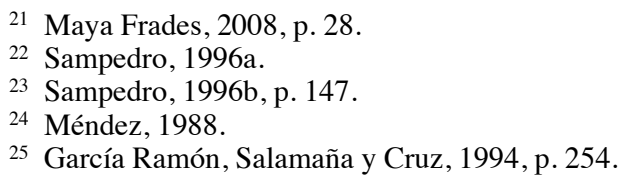


«La mujer casada dentro de la explotación familiar realiza trabajos de siembra, escarda, recolección, cuidados del ganado menor, etc., aparte de realizar todas las tareas del cuidado del hogar...

A pesar de la realidad de que la mujer contribuye de manera importante a la supervivencia de la agricultura familiar, este hecho no es reconocido socialmente, a la mujer no se la reconoce como trabajadora, sino simplemente como ayuda del marido, padre...; y en general, la mujer campesina se encuentra en una situación de inferioridad, en la que los propios organismos oficiales se desentienden de su situación» ${ }^{26}$.

Las campesinas pasaron de esta forma a un segundo plano - «segundona»- respecto al varón - «el gallo en escena»-, empresario, titular de la explotación y protagonista visible de la modernización agraria ${ }^{27}$. La implicación femenina en la actividad agraria, aún constituyendo una pieza básica del nuevo modelo agrario que se engendró en España en la década de los sesenta y setenta ${ }^{28}$, se fue pues delimitando cada vez más hasta quedar constreñida a tareas y faenas residuales, subordinadas, auxiliares, manuales, no mecanizadas y escasamente rentables, y a situaciones de ausencia masculina en explotaciones pequeñas o marginales que representaba una fuente secundaria de ingresos familiares ${ }^{29}$. Como indicaba la misma militante de la FUARM:

«[la agricultora] no tiene acceso a la capacitación agraria, ni a aumentar su formación como trabajadora de la agricultura, tiene dificultades a la hora de contar con su propia cartilla de la Seguridad Social, etc., y en la práctica la mujer campesina no es considerada como tal, sino como mujer del campesino, despreciándose de hecho toda la aportación que hace a la economía familiar con su trabajo» ${ }^{30}$.

Esta nueva división funcional de las responsabilidades y de los papeles en los procesos de producción y en la titularidad de los medios de producción de la agricultura afianzó en el medio rural un sistema de género que estableció modelos de feminidad y de masculinidad que marcaron la

${ }^{26}$ Cristina López García, «La situación campesina en la región de Murcia» (documento mecanografiado), F1M, Fondo: Secretaría Confederal de la Mujer de CC.OO, serie: Ponencias y comunicaciones, 11 de julio de 1980.

27 Vicente-Mazariegos y Porto, 1991, p. 16-17.

${ }_{28}$ García Ferrando 1975, p. 11; y García Bartolomé, 1992, p. 72.

29 Cànoves, García Ramón y Solsona, 1989, pp. 45-70.

30 Cristina López García, «La situación campesina en la región de Murcia», op. cit . 
desigualdad entre hombres y mujeres ${ }^{31}$. Aquellos modelos estaban envueltos en representaciones sociales provistas de prejuicios, significados, estereotipos, identidades y roles genéricos asentados y reiterados en el mito postmoderno del «idilio rural» que vincula de forma esencial la identidad femenina al hogar y a la familia, dos ámbitos que se entendieron como sus espacios de dominio y acción. Son abundantes las investigaciones empíricas que han destacado la importancia de la institución familiar en el medio rural en su doble dimensión, como soporte económico claro y como fuente de identidad social ${ }^{32}$. Esas mismas investigaciones sugieren que el modelo tradicional de mujer centrada en el hogar y la familia ha constituido - y constituye - un elemento de integración e identidad de la comunidad rural, por lo que ha existido - y existe - una gran presión social y moral hacia la implicación femenina con el cuidado y la reproducción de la vida. Esta implicación ha supuesto no solo asumir en solitario la gestión doméstica y el cuidado de las personas dependientes en el ámbito del hogar, sino también aceptar como algo normal y obligado el trabajo invisible en los negocios familiares, o el realizado a destajo y en condiciones muy precarias, de forma asalariada. Esta implicación ha condicionado también en gran medida la capacidad de las mujeres para hacerse cargo o emprender nuevos negocios o empresas. Muchas «emprendedoras» rurales se han visto condicionadas por «lealtad» hacia los negocios familiares que se sienten obligadas a continuar ${ }^{33}$.

El apego a esos vínculos y lealtades familiares ha contribuido a la discriminación y desvalorización del empleo de la mujer en la explotación agraria, catalogado como simple «ayuda familiar», y ha reforzado su rol tradicional de encargada del hogar. La persistencia de este modelo de domesticidad ha sido una de las mayores dificultades para conseguir, a pesar de los cambios impulsados por la legislación democrática, la plena igualdad de género en el medio rural y el debido reconocimiento del papel social y económico desempeñado por sus mujeres.

Las mujeres del mundo rural, pues, en plena democracia, continuaron siendo vulnerables frente a la carencia de garantías para la protección de sus derechos fundamentales, especialmente los derechos que tenían que ver con la valoración social de su trabajo, con el acceso a la tierra, con su reconocimiento como empresarias agrícolas y su participación en la

\footnotetext{
31 Esta tesis la encontramos en Cruz Souza, 2006.

32 García Ramón, Salamaña y Cruz, 1994.

33 Sampedro y Camarero, 2007, pp. 121-146.
} 
toma de decisiones ${ }^{34}$. Fuera del terreno estrictamente laboral, la mayoría de ellas han venido soportando un duro trabajo doméstico no compartido, agravado por la falta de equipamientos y la escasez de servicios.

$\mathrm{Al}$ objeto de no compartir el destino de sus madres, las jóvenes rurales comenzaron a desarrollar potentes estrategias de género todas ellas destinadas a romper con aquellos valores culturales y tradicionales, y con los referentes de identidad en los que habían sido socializadas las generaciones anteriores.

\section{Puentes para la igualdad. Sindicalismo y asociacionismo rural femenino para la transformación de las relaciones desigualitarias de género}

Esas transformaciones socio-económicas que estaba experimentado el mundo rural fueron esenciales en la construcción de identidades alternativas. Como advierten los especialistas, las nuevas formas de acumulación capitalista (postfordistas) provocaron en el mundo rural un proceso de reestructuración (rural restructuring) que tuvo un efecto inmediato en las relaciones sociales y en el consumo ${ }^{35}$. La introducción de valores posmodernos/postfordistas aportó una creciente complejidad en los estilos de vida y actitudes cotidianas de las mujeres del medio rural ${ }^{36}$. Tal circunstancia posibilitó un proceso de ruptura con las tipificaciones y representaciones sociales tradicionales y las relaciones de poder entre los géneros construidas históricamente. Y paralelamente favoreció, entre las mujeres rurales y agrarias, la construcción de «identidades elegidas» $\mathrm{y}$ «modelos transgresores» que abrían las puertas a su reconocimiento profesional y su visibilidad social.

Fue así que las jóvenes consiguieron que las mujeres del mundo rural dejaran de ser un colectivo silencioso para convertirse en otro visible e identificable. Parte de ese proceso ha sido explicado por ellas mismas. Su testimonio oral desvela que, desde fines de la década de los setenta, empezaron a constituirse en el seno de los sindicatos agrarios reuniones, informales en muchas ocasiones, organizadas por las afiliadas o por las propias representantes sindicales. Estos encuentros, como advertía la feminista y

\footnotetext{
34 Véase el trabajo citado de Ortega López, 2013, pp. 181-209.

35 Camarero y González, 2007, pp. 451-478.

36 Cruz Souza, 2006, p. 189.
} 
líder sindical agraria Lidia Senra, destinados a analizar su situación dentro y fuera de los sindicatos, se convirtieron muy pronto en espacios para el intercambio de unos objetivos, intereses, expectativas, experiencias y de unas vivencias personales y profesionales muchas veces de difícil consecución o compatibilización en el medio rural ${ }^{37}$. De esas reuniones resultó un diálogo fluido y una colaboración constante que, poco a poco, fue cristalizando en la conformación de una identidad propia marcada por su conciencia de las fuertes limitaciones personales en que vivían sus madres y ellas mismas. El contacto con los planteamientos y proclamas de orientación feminista les permitió fortalecerse conceptualmente (mediante la adquisición de categorías conceptuales básicas del pensamiento feminista) para rechazar así la exclusividad de lo doméstico y reclamar al mismo tiempo una mayor autonomía en sus vidas. La denuncia del escaso arraigo de los valores democráticos en los pueblos fue reiterada por estas mujeres. La democracia había traído derechos y libertades para el conjunto de la ciudadanía de uno y otro sexo, pero la democracia no había logrado acabar con el imaginario cultural que, interiorizando y asimilando la norma androcéntrica, legitimaba la asimetría de las relaciones entre los sexos. Los referentes en las comunidades rurales seguían marcando una clara diferencia entre las tareas asumidas y desempeñadas por uno y otro sexo, relegando a las mujeres al cuidado y a la reproducción, y a los varones al mantenimiento y a la producción.

Desde el interior de algunos sindicatos se formularon todo tipo de denuncias que tenía que ver, por ejemplo, con la precariedad socio-laboral que sufrían. Al carecer de un estatuto jurídico y social válido, al ser consideradas la mayoría como «ayuda familiar», muchas trabajadoras agrícolas no cobraban salario por lo que tampoco podían ser beneficiarias de una cobertura social apropiada, ni percibir indemnizaciones de paro, accidente o maternidad. La precariedad era, por tanto, la que definía las condiciones en las que efectuaban su trabajo estas mujeres Así lo reflejaba una ponencia presentada a las «Jornadas sobre la mujer del campo» organizadas por la Escuela Sindical de Comisiones Obreras:

«Hay un denominador común en los distintos tipos de trabajo que realiza la mujer campesina (ya sea como empresaria agrícola, como ayuda familiar, como asalariada, como empleada en la agroindustria, o como agricultora a tiempo parcial):

\footnotetext{
37 Este testimonio lo encontramos en el libro de Ledo Regal, 2010.
} 
- como mano de obra residual y sustitutoria

- como mano de obra sin cualificar

- con salarios más bajos que el varón

- condiciones de trabajo duras y penosas

Es siempre la subordinada en orden a la representación a la titularidad de las explotaciones, así como en la cartilla de la Seguridad Social y todas las gestiones de fuera de la casa». ${ }^{38}$

También hubo otras denuncias en torno a la discriminación salarial de la que eran objeto. En una ponencia elaborada por la Secretaría de la $\mathrm{Mu}-$ jer de CC.OO del Campo, las campesinas criticaban abiertamente el caso omiso que la patronal hacía de los acuerdos adoptados de «a igualdad de trabajo, igual salario», e incluidos en los convenios colectivos. Estas mujeres reconocían que sufrían todo tipo de presiones y coacciones (amenazas de no ser avisadas para trabajar en los cultivos de temporada) si no aceptaban jornales más bajos que los estipulados para los trabajadores agrícolas varones. ${ }^{39}$

Los patrones sexistas, y en consecuencia, desiguales, que imperaban en las instituciones democráticas, fueron también visualizados. El periódico aragonés El Día denunció en 1984 las actuaciones del Instituto Nacional de Reforma y Desarrollo Agrario (IRYDA), organismo autónomo de la Administración del Estado y dependiente del Ministerio de Agricultura. Las mujeres se dirigieron a este medio para señalar que el Instituto negó los derechos de una agricultora sobre un lote de tierras por considerar que «las mujeres no podían llevar tractores» ${ }^{40}$. Asimismo, el 28 de noviembre de 1984, una concejala del ayuntamiento de Don Benito (Badajoz), denunció, por considerarlas discriminatorias para la mujer, las bases de un concurso público para la adjudicación de fincas ${ }^{41}$.

A estas denuncias hay que sumar las acciones llevadas a cabo por las mujeres en su deseo de regularizar su situación ante la Seguridad Social.

38 Adoración Navasa Bonet, «La mujer rural y su trabajo en el sector agrario». Madrid, septiembre de 1992. F1M, Fondo: Secretaría Confederal de la Mujer de CC.OO., serie: Jornadas, Cursos, Seminarios, Conferencias, Exposiciones.

${ }^{39}$ F1M. Fondo: Secretaría Confederal de la Mujer de CC.OO.

40 Adoración Navasa Bonet, La mujer del campo y el trabajo de las agentes de extensión agraria, febrero de 1985, p. 5. F1M, Fondo: Secretaría Confederal de la Mujer de CC.OO., serie: Informes y estudios.

${ }^{41}$ Ibid. 
Hasta ese momento existía un bajo índice de afiliación de las agricultoras al Régimen Especial Agrario. Estar «dadas de alta» en la Seguridad Social era un elemento fundamental para que se les reconociera su estatus de trabajadora, tanto en el interior de la explotación familiar agraria como de cara a la administración pública. Sin embargo, este paso no resultó nada fácil. Las agricultoras se encontraron en muchas ocasiones con una dura resistencia que motivó el desencadenamiento de una serie de juicios en los que se vieron implicadas, de un lado, las campesinas, y de otro, la Seguridad Social ${ }^{42}$.

Junto a todas estas demandas, las mujeres del campo empezaron a exigir también el acceso a la formación profesional como paso previo a su reconocimiento - en términos sociales y jurídicos - como «agriculturas de pleno derecho». Como señalaban ellas mismas, en todos los programas ofertados por la administración pública era claramente perceptible un sesgo androcéntrico que las ignoraba. Las campesinas querían que se las incluyera en aquellos programas de profesionalización aprobados para el sector agrario y con los que se pretendía la conversión de los campesinos en empresarios agrícolas. No querían que únicamente se las tuviera en cuenta para formar parte de cursos cuyo fin principal era cualificarlas como «amas de casas» ${ }^{43}$. Tal circunstancia únicamente conseguiría mantener un contexto de mercados laborales restrictivos para las mujeres rurales. Se perpetuaría así la subsidiaridad de las mujeres en el ámbito agrario.

Y finalmente, otra denuncia que pronto empezaron a plantear las trabajadoras agrícolas, desde los años setenta, fue la de la titularidad compartida de la explotación agraria. En las unidades familiares, la adscripción a la figura de titular por un único miembro producía de facto una desigualdad cuando la actividad se realizaba en pareja, ya que de cara a la sociedad únicamente uno de ellos era el responsable y representante legal de la actividad. Generalmente, los titulares han sido los hombres mientras que las mujeres pasaban a denominarse, tal y como hemos señalado anteriormente, «ayuda familiar». Según el Censo

42 «Informe sobre el juicio de 3 mujeres de Foncea-Seguridad Social».F1M, Fondo: Secretaría Confederal de la Mujer de CC.OO., serie: Ponencias y comunicaciones, 16 de enero de 1980.

${ }^{43}$ Cristina López García, «La situación campesina en la región de Murcia» (documento mecanografiado).F1M. Fondo: Secretaría Confederal de la Mujer de CC.OO., serie: Ponencias y comunicaciones, 1980. 
Agrario de 1982, el 80,2 por 100 de los titulares de explotación agraria eran hombres frente al 19,8 por 100 que representan las mujeres. Por lo tanto, la figura de la titularidad única dificultaba la plena igualdad entre hombres y mujeres en el ámbito agrario y en el ámbito rural. Este contexto de desigualdad, tal y como plantean algunos trabajos ${ }^{44}$, tenía importantes consecuencias negativas. Primero porque jerarquizaba una relación compartida, transmitiendo desigualdades al interior de la familia y también proyectando al conjunto de la comunidad una situación de menor reconocimiento social de las mujeres. Y segundo, porque la titularidad única reproducía de forma fehaciente el régimen patriarcal, es decir, el hombre proveedor de sustento y la mujer proveedora de cuidado. No es de extrañar, por tanto, que este asunto de la titularidad compartida pronto se convirtiera en el gran caballo de batalla de las campesinas. Tal y como ellas mismas argumentaban, la titularidad compartida de las explotaciones agrarias tendría efectos cualitativos destacados que se plasmarían en las distintas dimensiones de las condiciones de vida de las mujeres (personales, familiares y comunitarias) ${ }^{45}$. El reconocimiento de facto de la capacidad de dirección de la actividad agraria produciría la legitimación de la actividad con cualificación profesional, lo que supondría al mismo tiempo la extinción de la figura obligada de «ayuda familiar» en la que se encuadraban muchas agricultoras (el 54,3 por 100 según el Censo Agrario de 1982). La figura de la titularidad compartida daría a las mujeres que se inscribiesen en el Registro la oportunidad de desarrollar su capacidad profesional como agricultoras titulares, visibilizando su trabajo en el sector. De este modo, se contribuiría a aumentar la participación de las mujeres en el empleo agrario. El medio rural dejaría de ser así un entorno social poco abierto y con escasas oportunidades para las mujeres. Del mismo modo, la cotitularidad permitiría el incremento de su participación y representación activa en un coto reservado hasta ese momento a los hombres: las organizaciones agrarias. Como titulares legalmente válidas, las campesinas pasarían a estar presentes por derecho propio en los órganos de toma de decisiones del sector agrario. Con ello se conseguiría, tal y como argumentaba el Secretario General de la Unión de Pequeños

${ }^{44}$ Cànoves, García Ramón y Solsona, 1989, pp. 45-70; García Bartolomé, 1992, pp. 71-97. Del mismo autor, 2002.

45 <www.magrama.gob.es/es/desarrollo-rural/temas/igualdad_genero_y_des_sostenible/titularidad_compartida/> 
Agricultores y Ganaderos (UPA), «un gran avance para la consecución de una igualdad real entre las mujeres y los hombres que viven y trabajan en el medio rural» ${ }^{46}$.

Paralelamente al planteamiento de estas denuncias, las jóvenes empezaron a llamar también la atención sobre aquella situación que tenía que ver con la ausencia casi absoluta de un mínimo de bienestar en su entorno inmediato (menos mercados, menos guarderías y colegios, escasez de entidades bancarias y alternativas de ocio, lejanía de los centros comerciales). Sobre las mujeres del medio rural pesaban la carencia de recursos o la mala utilización de los mismos, y la escasez de servicios e información ${ }^{47}$. Tal circunstancia redundaba en la idea de exclusión social que sufrían los habitantes del medio rural y, de forma particular, sobre sus mujeres. La consolidación de la estructura nuclear familiar, de la que se responsabilizaba en gran medida a las mujeres, que además habían interiorizado excesivamente la «generosidad hacia los suyos», las hacía las últimas beneficiarias de las mejoras sociales y estructurales que poco a poco se iban alcanzando en los municipios rurales. Como advertía el testimonio de una joven de la Federación de Uniones de Agricultores y Ganaderos de Burgos (FUAG):

«Las mujeres somos las que con más frecuencia vivimos y sufrimos las consecuencias de la mala sanidad y seguridad, es decir, de los malos servicios sanitarios e higiénicos que sufren las personas que viven en el medio rural» ${ }^{48}$.

Esta percepción de la realidad determinó que junto a las reivindicaciones esgrimidas por las trabajadoras agrícolas ante las autoridades públicas en materia laboral y económica, aquéllas también empezaran a formular reclamaciones destinadas a la mejora de sus condiciones de vida a través de la implantación de servicios públicos y la proyección de infraestructuras necesarias. El establecimiento en los pueblos de centros de asistencia médica con presencia de personal sanitario permanente fue una de

46 Ramos Silva, 2009, pp. 27-29.

47 Adoración Navasa Bonet, «La mujer del campo y el trabajo de las agentes de extensión agraria», febrero de 1985, p. 5. F1M. Fondo: Secretaría Confederal de la Mujer de CC.OO., serie: Informes y estudios, 1978-11 / 1994-10-21.

${ }^{48}$ F1M. Fondo: Secretaría Confederal de la Mujer de CC.OO., serie: Ponencias y comunicaciones, 1980-01-16 / 1989-04-24. 
las exigencias más repetidas por parte de las campesinas. Pretendían que estos centros sanitarios no sólo prestaran asistencia médica a los vecinos del municipio, sino que también realizaran cursos de Educación Sanitaria sobre las patologías ligadas a la actividad agropecuaria, e informaran, especialmente a las mujeres, sobre los programas de Planificación Familiar y Educación Sexual. Relacionada con la salud también estaba la reclamación de que se extendieran a las zonas rurales el sistema de seguros médicos y sociales que existía ya en las ciudades. Se trataba de evitar situaciones de desigualdad, como la que arrojaba una encuesta realizada en 1984 por el Centro de Investigaciones Sociológicas, entre las poblaciones rurales y las urbanas. Según esa encuesta realizada a mujeres de más de 18 años que habían dado recientemente a luz, el 50 por 100 de las que habitaban en municipios rurales y que tenían trabajo extra-doméstico, durante su última gestación habían tomado menos de una semana de descanso, frente al 24 por 100 del promedio general ${ }^{49}$.

También la educación y la cultura ocuparon buena parte de su decálogo de reivindicaciones. Demandaron en este sentido la instalación de guarderías, colegios, institutos, centros de Formación Profesional, con el fin de otorgar a la juventud rural las mismas oportunidades que a la juventud urbana. Incluso reclamaron la creación de escuelas de adultos para favorecer la completa alfabetización de los habitantes de los pueblos ${ }^{50}$.

Con estas reivindicaciones las mujeres más jóvenes del medio rural se convirtieron, a veces sin quererlo, en las portavoces de los problemas de los pueblos contribuyendo así a la plena consolidación de las comunidades locales en la nueva democracia.

Con denuncias y reivindicaciones como las que acabamos de exponer, estas mujeres incorporaron una perspectiva de género que contribuyó a visualizar la desigualdad existente en el medio rural, así como la función vital que las mujeres tenían en la agricultura y en el desarrollo rural de los pueblos. A través de aquella perspectiva, lograron abrir un amplio debate sobre «la cuestión de las mujeres del campo», su discriminación social y laboral. Un debate del que conviene decir que ha tenido un efecto de gran

49 Adoración Navasa Bonet, «La salud de la mujer en el medio rural», p. 9. Ponencia presentada a las VI Jornadas de la Secretaría de la Mujer-Comisiones Obreras, «Mujer, trabajo y salud».F1M. Fondo: Secretaría Confederal de la Mujer de CC.OO., serie: Jornadas, Cursos, Seminarios, Conferencias, Exposiciones, 1988-04-15 / 1989-10-30.

${ }^{50}$ F1M. Fondo: Secretaría Confederal de la Mujer de CC.OO, serie: Ponencias y comunicaciones, 1980-01-16 / 1989-04-24. 
calado, en la medida en que de él se han derivado políticas que tienen que ver con la igualdad de oportunidades ${ }^{51}$.

A lo largo de este tiempo, el desarrollo del asociacionismo rural femenino, al permitir a estas mujeres organizarse en torno a intereses comunes, ocupar espacios públicos y desplegar estrategias de acción colectiva, se ha mostrado como un instrumento básico para la participación ciudadana y el cambio social en la esfera pública ${ }^{52}$, donde todavía persisten también grandes desequilibrios, al tiempo que ha permitido contribuir al empoderamiento de las propias mujeres.

Dentro del amplio y diverso escenario del asociacionismo femenino que, desde la segunda mitad de los ochenta, y especialmente a partir de los noventa, se extendió por toda la geografía española ${ }^{53}$ favorecido por dos hechos que conviene no olvidar, de un lado, la creación del Instituto de la Mujer (1983), y de otro lado, el ingreso de España en la Unión Europea (1986), debemos mencionar en primer lugar a la Asociación de Familias y Mujeres del Medio Rural. AFAMMER nació en 1982 como organización pionera en España con un claro y primer objetivo: que las mujeres

51 Baste mencionar en este sentido las medidas gubernativas aprobadas en fechas recientes. El artículo 30 de la Ley Orgánica 3/2007 para la Igualdad Efectiva de Mujeres y Hombres hace referencia al principio de igualdad en la política de desarrollo rural. En él se establecen cinco medidas para transversalizar el enfoque de género y favorecer la igualdad entre varones y mujeres en ese medio. Por otro lado, la Ley 45/2007 para el Desarrollo Sostenible del Medio Rural tiene como objetivo principal el mantenimiento de la población rural a través de la mejora de su situación socioeconómica y el acceso a unos servicios públicos de calidad, poniendo especial énfasis en la incorporación de los jóvenes al mercado laboral, fomentando la igualdad de género y la participación de las mujeres en todos los ámbitos de la vida del medio rural. Su artículo 8 establece que todas las medidas contenidas en el Programa de Desarrollo Rural Sostenible, _-instrumento principal a través del cual tanto Administración General del Estado como las Comunidades Autónomas desarrollarán la citada ley -, deberán respetar el principio de igualdad de trato y oportunidades entre mujeres y varones. Del mismo modo, se contempla la posibilidad de establecer medidas de acción positiva a favor de las mujeres rurales, encaminadas a superar y evitar situaciones de discriminación de hecho por razón de sexo. Finalmente, la Ley 35/2011 de Titularidad Compartida de las Explotaciones Agrarias, que recoge una reivindicación histórica de las mujeres del campo, favorece inequívocamente la igualdad efectiva de género en el medio rural.

${ }^{52}$ El papel de las asociaciones de mujeres para el impulso de una ciudadanía activa y la transformación de las relaciones desigualitarias de género ha sido reseñada por diversos trabajos: Maquieira, 1995, pp. 263-328; Del Valle, 2001, pp. 131-151; Alba, 2003, pp. 36-39; Murillo y Rodríguez, 2003; Franco, Gilló y Sánchez García, 2005; Valiente, 2010, pp. 174-194; Infante, 2011, pp. 19-24.

53 Sánchez-Muros y Jiménez, 2012, pp. 1889-1910. 
rurales dejasen de ser invisibles y que su voz se escuchara en todos los foros nacionales e internacionales para alcanzar el reto de la igualdad real de oportunidades ${ }^{54}$. Con parecida intención, en septiembre de 1991 un nutrido grupo de mujeres se reunió en Ciudad Real ante la necesidad de constituir una asociación que trabajara en la defensa de los derechos e intereses de la mujer rural española. Surgió entonces la Federación de $M u$ jeres y Familias del Ámbito Rural (AMFAR) que planteó la igualdad de oportunidades para las mujeres rurales, el reconocimiento de su trabajo doméstico y profesional, la participación de la mujer rural en las actividades socioeconómicas y productivas, el incremento de su presencia en la toma de decisiones en la vida social, económica, laboral, política y cultural, el refuerzo de su formación profesional y cultural, el apoyo al carácter emprendedor y empresarial de las mujeres rurales, la incorporación de la mujer rural a todos los procesos del desarrollo rural sostenible, y la defensa de políticas sociales que garantizasen la conciliación de la vida familiar, personal y profesional ${ }^{55}$.

Ese mismo año se constituyó la Federación de la Mujer Rural (FEMUR) para luchar por la igualdad entre mujeres y hombres, por la igualdad laboral, social y económica, y por el reconocimiento del trabajo de las mujeres rurales. Entre sus programas de acción no han faltado aquellos destinados a atender problemas puntuales de las mujeres rurales que tienen que ver con la violencia machista, el abandono de sus lugares de origen, las carencias económicas y el apoyo para la creación de empresas, asesoramiento, apoyo y técnicas de gestión ${ }^{56}$.

La Confederación de Mujeres del Mundo Rural, CERES, se fundó el 30 de enero de 1997 con la finalidad de aportar soluciones a los problemas del medio rural, en general, y específicamente, a los que afectan a las mujeres rurales, limitando su desarrollo personal, profesional, familiar y social $^{57}$.

La Federación de Asociaciones de Mujeres Rurales (FADEMUR), que nació en 2004 ligada a la Unión de Pequeños Propietarios (UPA), ha aunado y reforzado el esfuerzo de las asociaciones de mujeres rurales que

${ }^{54}$ AFAMMER cuenta en la actualidad con unas 180.000 socias y tiene presencia en la práctica totalidad de las Comunidades Autónomas, http://www.afammer.es/que-es-afammer.html.

$55<$ http://mujerrural.com/quienessomos.asp $>$.

$56<$ http://femur.es/que-es-femur/>.

$57<$ http://www.ceres.org.es/quienessomos.php>.

Historia Contemporánea 54: 115-143 
la constituyen. Desde su aparición ha pretendido superar las dificultades que las mujeres encuentran en el medio rural para acabar con la dependencia y la discriminación, tanto en el ámbito sociolaboral - condiciones de empleo, seguridad, cobertura social - como en la participación social e institucional que sufren las mujeres rurales. Mediante la denuncia de situaciones de discriminación y desigualdad, ha contribuido a mejorar su formación y su capacitación, y ha reivindicado el reconocimiento del papel que las mujeres han desempeñado en la estabilidad y el desarrollo del mundo rural. Asimismo, sus integrantes han trabajado para que desaparezca la triple discriminación en la que tradicionalmente han vivido las mujeres rurales, al ejercer una actividad económica sometida a grandes incertidumbres, en un entorno muy masculinizado y en un medio con poco apoyo social para la realización de las tareas familiares ${ }^{58}$.

\section{Conclusiones}

Con la democracia, las sociedades rurales se hicieron más abiertas y globales. Las diferencias entre lo rural y lo urbano se fueron aminorando y ello quedó plasmado en sus habitantes, en sus objetivos, en sus expectativas, en sus intereses. La población más joven de los pueblos, especialmente las mujeres, se vio afectada por esa apertura social y política que vivió España tras dejar atrás la dictadura de Franco. Sin embargo, la conquista de valores exaltadores de los principios de la Libertad, la Igualdad, la Democracia, el Estado de Derecho, la Representatividad, el Constitucionalismo y los Derechos Humanos, entre otros, no puso fin a aquellos otros valores, comunitarios y familistas, característicos del mundo campesino más tradicional y que implicaban la asignación de roles femeninos claros y diferenciados de los roles masculinos ${ }^{59}$. La categorización social del trabajo femenino como «secundario» o «auxiliar» respecto al masculino, en el marco familiar, ha tenido, por ejemplo, una acentuada vigencia en el medio rural, en la medida en que los roles familiares han adquirido para la mujer un carácter mucho más perentorio, tanto en la práctica como en la ideología ${ }^{60}$.

\footnotetext{
$58<$ http://www.fademur.es/_contenido/quees.php>.

59 Sampedro Gallego, 2008, p. 90.

60 Sampedro 1991, p. 32.
} 
La convivencia en la sociedad rural de modelos de relación tradicional, donde el papel de la mujer ha sido secundario y pasivo, y un mundo marcado por pautas de modernidad urbana, que prima un comportamiento individualizado sobre el colectivo, gestó un escenario potencialmente conflictivo entre géneros en el que las mujeres emergieron con un protagonismo que históricamente se les había negado.

La documentación utilizada en nuestro trabajo desvela a unas jóvenes modernas, con una actitud más distante respecto a los agentes tradicionales de socialización y poco proclives a asumir un orden dado sin un cuestionamiento del mismo. En este escenario, la perspectiva de género se ha revelado como una condición imprescindible en el desarrollo rural. Una perspectiva que ha sido transmitida por las organizaciones de mujeres conformadas en ese medio tras la consecución de la democracia en nuestro país. Sus reivindicaciones, tal y como reza en muchas de los trabajos de investigación en los que nos hemos apoyado, han sido una pieza clave de sus estrategias de género, y han constituido desde 1977 una contundente herramienta para armonizar la asimetría de las relaciones de género presentes en sectores tradicionalmente muy masculinizados como es el caso de la agricultura.

Ante el nuevo contexto histórico que brindaba la democracia, las asociaciones femeninas rurales - ya sean las de carácter más reivindicativo como las destinadas a la prestación de servicios - se convirtieron, a decir por sus propias representantes, en «agentes de cambio» eficaces para la transformación de las relaciones desigualitarias de género más allá del ámbito estrictamente laboral, haciendo ver que la igualdad era un asunto de justicia social y, por tanto, mujeres y hombres eran responsables y, mujeres y hombres iban a resultar beneficiados ${ }^{61}$. Convertirse en portavoz ante los diferentes foros - nacionales e internacionales - de las diferentes problemáticas que rodean a las mujeres que habitan y trabajan en el campo, así como la aplicación efectiva de la legislación en pos de la igualdad aprobada en fechas más o menos recientes, han sido las tareas prioritarias efectuadas por estas asociaciones desde su constitución.

\footnotetext{
${ }^{61}$ Así se refería a ellas la presidenta nacional de la Asociación de Familias y Mujeres del Medio Rural (AFAMMER) y también presidenta de la Comisión de Igualdad del Congreso de los Diputados, Carmen Quintanilla, <http://www.afammer.es/noticias/noticiaseventos/189-quintanilla-destaca-el-papel-primordial-de-las-asociaciones-de-mujeres-como-agentes-de-cambio-y-portavoces-de-los-ciudadanos.html>.
} 
En palabras de Teresa López, presidenta de la Federación de Asociaciones de Mujeres Rurales (FADEMUR):

«Las organizaciones de mujeres rurales han permitido que las mujeres tengan un lugar de reunión, de conocimiento mutuo, de intercambio de experiencias y saberes. Han supuesto un instrumento de interlocución con las distintas Administraciones Públicas: nos visibilizamos, denunciamos las situaciones de discriminación que vivimos, reclamamos soluciones y, sobre todo, planteamos soluciones» ${ }^{62}$.

En suma, y a tenor de lo explicado, debemos considerar este asociacionismo como algo crucial. Primero, porque las asociaciones de mujeres rurales se presentan como grandes articuladoras de la democracia participativa en el terreno social y político, y segundo, porque sus actuaciones han supuesto un claro avance hacia la igualdad de género en aquellos espacios públicos de poder y de toma de decisiones en los que aún sigue persistiendo una clara desigualdad entre hombres y mujeres.

\section{Fuentes}

F1M: Fundación $1 .^{\circ}$ de Mayo. Archivo del Trabajo de Comisiones Obreras (Madrid)

\section{Bibliografía}

Agarwal, Bina, «Who Sows? Who Reaps? Women and Land Rights in India», The Journal of Peasant Studies, Vol. 15, 4, july, 1998, pp. 530-581.

Aguilar CRiado, Encarnación et al., Mujeres Trabajadoras en el Mundo Rural Andaluz, Etnología Monografías, Sevilla, 2001.

AlBA, Teresa, «Las asociaciones de mujeres como nuevo sujeto social», Revista Meridiam, 2(29), 2003, pp. 36-39.

ARNÁIZ DE LAS REVILLAS, Ana, «La cooperación, la asociación y las redes como herramienta fundamental de trabajo para promover la integración de la mujer en el desarrollo rural», en La mujer: clave del desarrollo rural, Junta de Andalucía, Consejería de Agricultura y Pesca de Andalucía, Jaén, 1999, pp. 65-69.

${ }^{62}$ Revista de Desarrollo Rural, 35, marzo, 2007, p. 6. 
CAmarero, Luis y GonzÁlez, Manuel, «Desarrollo y reestructuración Rural. Reflexiones acerca del desarrollo local», en PÉREZ Rubio, José Antonio (coord.): Sociología y Desarrollo. El reto del desarrollo sostenible, Ministerio de Agricultura, Pesca y Alimentación, Madrid, 2007, pp. 451-478.

CAMARERO, Luis, «Pautas y tendencias demográficas del medio rural: la población rural en la última década del siglo XX», en GonZÁlez, Juan Jesús y GóMEZ Benito, Cristóbal (coord.), Agricultura y Sociedad en el cambio de siglo, McGraw Hill y UNED, Madrid, 2002, pp. 63-78.

CAmarero, Luis, Del éxodo rural y del éxodo urbano. Ocaso y Renacimiento de los asentamientos rurales en España, Ministerio de Agricultura, Pesca y Alimentación, Madrid, 1993.

CÀnoves, Gemma, García Ramón, María Dolores y Solsona, Montserrat, «Mujeres agricultoras, esposas agricultoras: un trabajo invisible en las explotaciones familiares», Revista de Estudios Agrosociales, 147, enero-marzo, 1989, pp. 45-70.

Cruz SouzA, Fátima, Género, Psicología y Desarrollo Rural: la construcción de nuevas identidades, Ministerio de Agricultura, Pesca y Alimentación, Madrid, 2006.

DEERE, Carmen Diana y LEón, Magdalena, Género, propiedad y empoderamiento: tierra, Estado y mercado en América Latina, TM editores, Colombia, 2000.

Del Valle, Teresa, «Asociacionismo y redes de mujeres. ¿Espacios puente para el cambio?», Anuario de Hojas de Warmi, 12, 2001, pp. 131-151.

DíAz MÉNDEZ, Cecilia, «Aproximaciones al arraigo y al desarraigo femenino en el medio rural: mujeres jóvenes en busca de una nueva identidad rural», Papers: revista de sociología, 75, 2005, pp. 63-84.

Franco, Pepa, Gilló, Clara y SÁnchez García, Laura, Movimiento asociativo de mujeres y las políticas locales de igualdad. La participación de las asociaciones en las políticas locales de igualdad, Federación Española de Municipios y Provincias/Federación Andaluza de Municipios y Provincias, Sevilla, 2005.

GARCía BARTOLOMÉ, José Manuel, «El trabajo de la mujer agricultora en las explotaciones familiares agrarias españolas», Revista de Estudios Agrosociales, 161, 1992, pp. 71-97.

García BARTOLOMÉ, José Manuel, Mujeres rurales en España. Análisis crítico de la producción documental (1990-2002), MAPYA, Madrid, 2002.

GARCÍA FERRANDO, Manuel, «Mujer y trabajo en la sociedad rural española. Estudios de casos», Revista de Estudios Agrosociales, 92, 1975, pp. 7-63.

GARCÍA FERRANDO, Manuel, Mujer y sociedad rural: un análisis sociológico sobre trabajo e ideología, Madrid, Cuadernos para el Diálogo, 1977.

GARCíA RAMÓN, Dolores, Salamaña, Isabel y Cruz, Josefina, Mujer y agricultura en España. Género y Trabajo, Oikos Tau, Barcelona, 1994.

GonZÁlez, Juan Jesús y Gómez BENITO, Cristóbal, Juventud Rural 2000, INJUVE, Ministerio de Trabajo y Asuntos Sociales, Madrid. 2002. 
GuHA, Ranahit, Las voces de la historia y otros estudios subalternos, Crítica, Barcelona, 2002.

Herrera, Antonio and Markoff, John, «Rural Movements and the Transition to Democracy in Spain», Mobilization: An International Quarterly, Vol. 16, No. 4, 2011, pp. 455-474.

HERRERA, Antonio et al., «Propuestas para la reinterpretación de la historia de Andalucía: recuperando la memoria democrática», Ayer, 85, 2012, pp. 73-96.

HerrerA, Antonio, «La democratización de la Democracia. La Transición en los municipios andaluces (1977-1979)», Alcores: revista de historia contemporánea, 14, 2012, pp. 117-138.

HERrERA, Antonio, «Los procesos de democratización durante la transición española. Viejos debates, nuevas propuestas», Historia social, 71, 2011, pp. 161179.

INFANTE, Nina, «Asociaciones de mujeres y ciudadanía activa. La participación en el periodo 2007-2010», en Elecciones 2011. Igualdad y participación de las asociaciones de mujeres, Coordinadora de Organizaciones de Mujeres para la Participación y la Igualdad, Madrid, 2011, pp. 19-24.

Ledo Regal, Tareixa, Lidia Senra Rogríguez. A historia dun liderado entrañable, Laiovento, A Coruña, 2010.

MaquiEIRA, Virginia, «Asociaciones de mujeres en la comunidad autónoma de Madrid», en ORTEGA LóPEZ, Margarita (dir.), Las mujeres de Madrid como agentes de cambio social (pp. 263-328), Universidad Autónoma, Madrid, pp. 263-338.

MAYA FrADES, Valentina, «Señas de identidad de la mujer rural», en MAYA FRADES, Valentina (ed.), Mujeres rurales. Estudios multidisciplinares de género, Ediciones de la Universidad de Salamanca, Salamanca, 2008, pp. 17-23, p. 28.

Medina MARín, Rosa, «Feminismos periféricos, feminismos-otros: una genealogía feminista decolonial por reivindicar», Revista Internacional de Pensamiento Político, 8, 2013, 53-79.

Medina Martín, Rocío, «Feminismos periféricos, Feminismos-otros: una genealogía feminista decolonial por reivindicar», Revista Internacional de Pensamiento Político, I Época, 8, 2013, pp. 53-79.

Mendez, Lourdes, «Cousas de mulleres'. Campesinas, poder y vida cotidiana (Lugo 1940-1980)», Antropos, Barcelona, 1988.

MEndez, Lourdes, Cousas de mulleres. Campesinas, poder y vida cotidiana (Lugo 1940-1980), Antropos, Barcelona, 1988.

MohanTy, Chandra Talpade, «Bajo los ojos de occidente: Academia Feminista y discurso colonial», en SuÁREZ NAVAZ, Liliana y HERnÁndEZ, Aída (eds.), Descolonizar el feminismo: teorías y prácticas desde los márgenes, Cátedra, Madrid, 2008, pp. 112-161.

Murillo, Soledad y Rodríguez, Rocío, Ciudadanía activa. Asociacionismo de mujeres, Consejo de Mujeres de la Comunidad de Madrid, Madrid, 2003. 
ORTEGA LóPEz, Teresa María, «Campesinas. Nuevos sujetos para la investigación histórica», Alcores: revista de historia contemporánea, 14, 2012, pp. 51-69.

ORTEGA LóPEZ, Teresa María, «Democratizando la democracia. Estrategias de género de las trabajadoras agrícolas españolas (1977-1990)», Historia agraria: Revista de agricultura e historia rural, 61, 2013, pp. 181-209.

ORTEGA LOPEZ, Teresa María, «Les graines du changement. Les paysannes espagnoles pendant le franquisme, la Transition et la démocratie», en BERGES, Karine Burgos-Vigna, Diana, Yusta Rodrigo, Mercedes y Ludec, Nathalie (dir.), Résistantes, militantes, citoyennes. L'engagement politique des femmes aux XXe et XXIe siècles, Presses Universitaires de Rennes, Rennes, 2015, pp. 61-74.

Pablo Cervera, Trinidad, Pérez Segovia, Ruth y Vargas Llovera, María Dolores, «Mujer, familia y mundo rural: dos modelos para un cambio social», Alternativas: cuadernos de trabajo social, n. ${ }^{\circ} .3,1995$, pp. 85-93.

RAMOS SILVA, Lorenzo, «La participación de las mujeres en la toma de decisiones», Agricultura familiar en España, 2009, pp. 27-29.

SAMPEDRO, Rosario, «El mercado de trabajo en el medio rural: una aproximación a través del género», Política y Sociedad, 8, 1991, pp. 25-33.

SAMPEDRO, Rosario Género y ruralidad. Las mujeres ante el reto de la desagrarización, Ministerio de Trabajo y Asuntos Sociales, Instituto de la Mujer, Madrid, 1996a.

SAMPEDRO, Rosario, «Mujer y ruralidad: un análisis de las relaciones de género desde la perspectiva del hábitat», en García de León, M. ${ }^{a}$. A., GARCíA DE CortázAr, M. y OrTEGA, F. (coords.), Sociología de las mujeres españolas, Editorial Complutense, Madrid, 1996b, pp. 137-157.

SAMPEDRO, Rosario, «Como ser moderna y de pueblo a la vez: los discursos del arraigo y del desarraigo en las jóvenes rurales», Revista de Estudios de la Juventud, 83, 2009, pp. 179-193.

SAMPEDRO, Rosario y CAMARERO, Luis, «Mujeres empresarias en la España rural. El sujeto pendiente del desarrollo», Revista Internacional de Sociología, 48, 2007, pp. 121-146.

SÁNCHEZ-Muros, Sonsoles y Jiménez, María Luisa, «Mujeres rurales en movimiento: sociografía del asociacionismo de mujeres en la provincia de Granada», en VÁZQUEZ BERMúDEZ, Isabel (coord.), Investigación y género, inseparables en el presente y en el futuro: IV Congreso Universitario Nacional «Investigación y Género», Sevilla, 21 y 22 de junio de 2012, pp. 1889-1910.

SANTISO SANZ, Raquel, «Hombres y mujeres en el medio rural: el caso del Somontano de Barbastro», Acciones e Investigaciones Sociales, 15, 2002, pp. 159-194.

VAliEnte, Celia, «The Women's Movement, Gender Equality Agencies and Central-State Debates on Political Representation in Spain», en LOVENDUSKI, Joni (ed.), State Feminism and Political Representation, University Press Ortbals, Cambridge, 2010, pp. 174-194. 
ViCENTE-MAZARIEGOS, Josechu et al., «La mujer en las estadísticas oficiales», en ViCEnTE-MAZARIEGOS, Josechu et al., Situación socioprofesional de la mujer en la agricultura, Tomo II, Ministerio de Agricultura, Pesca y Alimentación, Madrid, 1991.

Vicente-Mazariegos, Josechu y Porto VÁzQuez, Fernando, «La implicación de la mujer en la agricultura familiar: apuntes sobre el proceso de desagrarización de España», Política y sociedad, 9, 1991, pp. 15-28.

ZAPATERo Molinero, Sara y JimÉnez MeJíAs, Rafael, La mujer en la explotación agraria familiar: estudio de una zona aragonesa, Centro Regional de Investigación y Desarrollo Agrario del Ebro, Zaragoza, 1980.

\section{Financiación}

Proyectos «El largo camino hacia la democracia: cambio económico, movimientos sociales y construcción identitaria en la España meridional (1959-1979)», HUM2006-14138-C06, y «La construcción de la democracia en el mundo rural andaluz (1973-1982)», PRY054/11.

\section{Datos de la autora}

Teresa María Ortega-López (tm.ortega@ugr.es) es Profesora Titular de Historia Contemporánea en la Universidad de Granada. Ha centrado su investigación en la implantación y desmoronamiento del régimen franquista, en el análisis de los discursos del antifeminismo generados por la derecha antiliberal española, y en el papel de las campesinas en la Transición Política. Es autora del libro Del Silencio a la Protesta. Explotación, pobreza y conflictividad en una provincia andaluza, Granada 1936-1977 (2003). Asimismo, es coautora del libro: Franquismo y Posguerra en Andalucía Oriental, (2005), y del artículo: «The Stability and Consolidation of the Francoist Regime. The Case of Eastern Andalusia, 1936-1950" (Contemporary European History, 20, 1, February 2011). En 2011 coeditó los libros: La España Rural. Siglos XIX y XX. Aspectos políticos, sociales y culturales; y Feminismos y Antifeminismos. Ciudadanía, culturas políticas e identidad de género en la España del siglo XX. Recientemente ha publicado «Democratizando la democracia. Estrategias de género de las trabajadoras agrícolas españolas (1977-1990)", en la revista Historia Agraria (n. ${ }^{\circ}$ 61, 2013) y el libro Jornaleras, campesinas y agricultoras. La historia agraria desde una perspectiva de género (2015). 
